\title{
Procrastinação e aprendizagem acadêmica
}

\begin{tabular}{lr}
\hline Bárbara Alves Branco Machado & Governo do Estado do Rio Grande do Sul. Professora estadual, Bagé. \\
& E-mail: balvesmachado56@gmail.com \\
\hline Suzana Schwartz & Universidade Federal do Pampa (UNIPAMPA). \\
& E-mail: sznschwartz@gmail.com \\
\hline
\end{tabular}

\author{
Recebido: 12 fev. 2018. Revisado: 06 abr. 2018. Aceito: 12 abr. 2018. \\ DOI: http://dx.doi.org/10.21674/2448-0479.41.119-135
}

\section{Resumo}

Esse estudo foi realizado no contexto do componente curricular Metodologia de Pesquisa, em um curso de licenciatura, no qual a proposta foi a de aprender pesquisar na prática. O tema, escolhido pelo grupo de alunos, foi a procrastinação em âmbito universitário, com o objetivo de compreender se ela contribui negativamente para o desempenho acadêmico. O motivo da escolha do tema foi a percepção da recorrência do fenômeno no contexto de inserção, inclusive entre os participantes. A pesquisa enfatizou a abordagem qualitativa, utilizando como instrumento metodológico entrevistas semiestruturadas, gravadas, transcritas e analisadas através da Análise de Conteúdo. Os resultados indicam que a elaboração de uma estratégia de organização de tarefas pode contribuir para minimizar a procrastinação acadêmica, porém ideias como "automatismo de repetição" iniciando, muitas vezes, cursos com atitudes e procedimentos aprendidos em contextos escolares diferentes, no modo "cumprir tarefa", sem que os alunos sejam acolhidos com a explicitação das mudanças de expectativas, sem perceber que aprender pode ser significativo e prazeroso, quando explicitados os "objetivos" os "procedimentos", os "critérios avaliativos", contribuíram para que os alunos/pesquisadores refletissem criticamente, percebendo que, ao longo dessa experiência não haviam procrastinado tarefas e que tinham aprendido metodologia de pesquisa na prática, realizando uma que está sendo compartilhada nesse artigo.

Palavras-chave: Procrastinação acadêmica. Desempenho acadêmico. Pesquisa acadêmica.

\section{Abstract \\ Procrastination and academic learning.}

This study was carried out in the context of the curricular component Research Methodology, in a degree course, in which the proposal was to learn to research in practice. The theme, chosen by the group of students, was the procrastination at university level, to understand if it contributes negatively to the academic performance. The reason for choosing the theme was the perception of the recurrence of the phenomenon in the insertion context, as well as among the participants. The research emphasized the qualitative approach, using as methodological instrument semi-structured interviews, recorded, transcribed, and analyzed through Content Analysis. The results indicate that the elaboration of a strategy of task organization can contribute to minimize academic procrastination, but ideas such as "repetition automatism" often initiating courses with attitudes and procedures learned in different school contexts, without being welcomed with the explicit changes in expectations, without realizing that learning can be meaningful and enjoyable, when the "objectives "and" procedures ", the 
"evaluative criteria" were explained, contributed to the students/researchers to reflect critically, realizing that throughout this experience they had not procrastinated tasks and that they had learned research methodology in practice, performing one that is being shared in that article.

Keywords: Academic procrastination. Academic performance, academic research.

\section{Introdução e contextualização da temática}

O ingresso na universidade é uma experiência significativa na trajetória pessoal, com expectativas de vivências positivas. Durante o processo de reconhecimento do novo contexto, fatores como as estratégias para o acolhimento e para a permanência dos ingressantes, as características pessoais dos sujeitos envolvidos, a qualidade dos processos de ensino e de aprendizagem oferecidos pela instituição, contribuem para a inserção e/ou adaptação dos estudantes na cultura universitária e para a motivação de nela permanecer e/ou evadir.

Ao longo da vivência escolar, os alunos vão aprendendo modos de ser, de estar nesse espaço, desenvolvendo maneiras de atender as demandas de cada componente curricular e/ou docente. Conhecimentos tácitos sobre as estratégias didáticas de cada professor, o tipo de trabalhos solicitados, as expectativas de desempenho e o modo de avaliar vão sendo "transmitidos" entre os discentes informalmente, contribuindo, algumas vezes, para a manutenção de atitudes caracterizadas como "automatismos de repetição" (FREUD, 2004) ${ }^{1}$, frente a realização ou não de tarefas.

Quando ingressam no ensino superior, a representação social, que já construíram sobre as instituições de ensino, seus modos de funcionar, o tipo de tarefas que solicitam, é trazida, conscientes ou inconscientemente, pelos estudantes, que tentam "encaixá-la" na nova realidade. Geralmente, eles não são preparados para a transição da educação básica para o ensino superior, especialmente no que tange aos tipos de trabalhos que serão exigidos, a sua quantidade e nem quanto as especificidades das expectativas dos diferentes componentes curriculares e/ou docentes, o que, muitas vezes contribui para o uso da estratégia de procrastinação com as tarefas, o que pode atrapalhar no rendimento acadêmico.

No contexto do ensino superior no Brasil ${ }^{2}$, há o não preenchimento de vagas de muitos cursos das universidades públicas e índices significativos de evasão dos alunos, gerando desperdícios acadêmicos, sociais e econômicos. Por ausência de candidatos, nem todos os cursos oferecidos têm suas vagas preenchidas, e o índice de evasão dos alunos (de $17 \%$ a 38\%, dependendo o curso analisado), são fatos que evidenciam a existência de múltiplos fatores a serem analisados, para a explicação/compreensão/encaminhamentos para modificar o quadro atual.

Nossa hipótese, elaborada com base na revisão teórica sobre a evasão e a retenção no ensino superior (BAGGI; LOPES, 2011; NUNES, 2013, SILVA, 2012; SILVA FILHO, 2007; POLYDORO, 2000), é que estão relacionados com motivos de ordem pessoal, como a inadequação da escolha profissional, e os contextuais, nos quais estão inclusas as estratégias didáticas utilizadas, que oportunizam ou não que os alunos ressignifiquem os conteúdos propostos, dentre outros.

A evasão é indicativa de falhas no processo de ensino e ineficácia do serviço prestado, além de um aumento nos gastos financeiros, pois a mesma estrutura acadêmica que deveria

\footnotetext{
Ato que se repete sem a consciência do sujeito (FREUD. Caso Dora. Biblioteca Nueva, 1973).

2 Disponivel em <http://portal.mec.gov.br/sesu/arquivos/pdf/ensinosuperiormundobrasiltendenciascenarios2003-2025.pdf> Acesso: em 20 ago. 2017.
} 
atender determinado grupo inicial estaria sendo destinada a um quantitativo menor de alunos (SILVA et al. p. 392, 2012).

Nesse contexto, brevemente comentado, a procrastinação acadêmica, atitude recorrente de inúmeros estudantes diante de propostas de atividades em diferentes componentes curriculares, e tema desse artigo, pode ser um dos sintomas relacionados a problemas no ensino e na aprendizagem, que culminam em evasão e/ou retenção, justificando o estudo.

Realizamos a pesquisa no componente curricular "Metodologia da Pesquisa", ofertado no segundo semestre de 2016 aos estudantes dos cursos de licenciatura de uma universidade federal. A professora, depois de algumas aulas expositivas dialogadas iniciais, nas quais apresentou conceitos básicos explicitando partes de uma investigação científica, propôs que aprendêssemos pesquisa na prática, realizando os passos básicos de uma: escolha e delimitação do tema, elaboração dos objetivos e da justificativa, escolha da metodologia e a redação das considerações finais. Aprender pesquisa, fazendo pesquisa.

Os alunos aceitaram a proposta e escolheram como tema a procrastinação de tarefas acadêmicas, justificando a escolha com o argumento da significativa ocorrência dessa atitude entre os acadêmicos, inclusive entre os participantes desse grupo de pesquisa, e também porque havia a hipótese inicial de que, esse comportamento influenciava negativamente no rendimento discente.

Após a escolha e a delimitação do tema, foram decididos o método, os instrumentos metodológicos para a coleta e a análise de informações, com base no que já havíamos estudado e reconstruído no componente. Como a pesquisa objetivava compreender um fenômeno, optamos por uma abordagem qualitativa (MINAYO, 2002; GERHARDT; SILVEIRA, 2009). Escolhemos como instrumento metodológico a entrevista semiestruturada e os sujeitos da pesquisa seriam colegas do curso que concordassem em participar do estudo. As entrevistas foram gravadas e transcritas, possibilitando o uso da análise do conteúdo textual e discursivo (GALLIAZI; MORAES, 2006; MORAES, 2003), como instrumento de análise das informações coletadas.

Em relação ao Comitê de Ética em Pesquisa (CEP) é necessário frisar novamente que a investigação teve como contexto o componente curricular eletivo Metodologia da Pesquisa. Durante as aulas dessa disciplina, foi comentado com os alunos sobre a função e o papel do CEP, e o que era necessário para viabilizar o procedimento burocrático, que, pelo tempo de demora, acabaria inviabilizando a realização da nossa pesquisa. Por esse motivo, optamos pela assinatura do termo de consentimento substanciado dos sujeitos participantes, aos quais foram assegurados sigilo e comportamento ético com as informações. Portanto, como não havia tempo hábil para realizar o processo com o CEP, não efetivamos o trâmite.

A seguir, vamos descrever uma síntese do percurso metodológico, esclarecendo sinteticamente o referencial teórico em que o estudo foi embasado, a triangulação com algumas falas dos entrevistados, que convergiram em vários aspectos, bem como nossas conclusões parciais e as aprendizagens reconstruídas no processo.

\section{Percurso metodológico}

Iniciamos a pesquisa cientes de que, a análise crítica reflexiva de qualquer fenômeno que se deseja compreender através de uma pesquisa científica, necessita partir do pressuposto de que o objeto de estudo é uma parte de um todo complexo (MORIN, 2003) e, que a compreensão do fenômeno investigado é dependente-autônoma (MORIN, 2000) da compreensão das partes que o constituem e que influenciam para a sua existência. Foi necessário, portanto, "procurar as relações e 
inter-retro-ações entre cada fenômeno e seu contexto, as relações de reciprocidade todo/partes [...] (MORIN, 2000, p.25), para descrevê-lo, analisá-lo, interpretá-lo, compreendê-lo.

Nosso objeto de estudo foi a procrastinação acadêmica. Como tal, iniciamos definindo-o conceitualmente como um acontecimento caracterizado pelo adiamento de tarefas principalmente em situações que exigem o cumprimento de prazos. O motivo desencadeador do nosso interesse por realizar uma pesquisa científica sobre esse tema, foi a percepção empírica do número alarmante de discentes e docentes que a praticam na universidade, independente do curso.

Porém, esse motivo não seria suficiente para investirmos tempo, pensamento e produção textual, dentre outros esforços que uma pesquisa científica demanda, ao tema. Essa é apenas uma parte no todo que justifica a pesquisa. Que problemas, que consequências negativas, poderiam ser atribuídos a procrastinação de tarefas acadêmicas? Que partes poderiam lhe caber no todo referente às expectativas não atendidas dos egressos? Para a qualidade dos processos de ensino e de aprendizagem? Para o rendimento dos acadêmicos?

Percebemos que é função social da universidade oportunizar situações que contribuam para a (auto) formação de sujeitos habilitados a produzir, compartilhar conhecimento que qualifique as vidas das pessoas. Quais consequências a procrastinação de tarefas poderia ter para dificultar o atendimento do papel social da universidade? Será que existe algum tipo de relação entre os índices de evasão e retenção e a procrastinação de tarefas?

Encontrar "respostas" para esses questionamentos e/ou ideias iniciais que tínhamos sobre o tema poderia contribuir para a compreensão de suas possíveis consequências/influencias negativas no contexto da qualidade dos processos de ensino e de aprendizagem da universidade. Esse motivo, aliado à nossa percepção empírica do uso frequente da procrastinação no nosso curso, o número de alunos concluintes, o de alunos evadidos ao longo do curso, e o cenário educacional comentado no início desse artigo, justificaram o estudo e validaram empenho de esforços na realização da pesquisa.

O rendimento do estudante, seu investimento pessoal e a participação ativa no seu processo de formação universitária são fenômenos, relacionados com a procrastinação, que tem também chamado a atenção de outros pesquisadores (SANTOS, 2000; GARCIA et al., 2015), e os resultados dos seus estudos permitem supor que, em muitos cursos, os egressos não estão alcançando as expectativas institucionais em relação a reconstrução de competências e habilidades esperadas.

Nesse sentido, iniciamos o estudo com uma revisão bibliográfica, procurando investigar o que outros teóricos escreveram sobre o tema em si, e sobre conceitos que julgamos, inicialmente, estarem relacionados com a procrastinação: rendimento, aprendizagem, avaliação, entre outros.

\section{Referencial teórico}

A elaboração do referencial teórico partiu da necessidade de explicitar os objetivos do estudo. Baseado nas nossas hipóteses iniciais que muitos alunos procrastinavam e que essa atitude prejudicava o rendimento acadêmico, definimos como objetivo o de compreender se a procrastinação influencia negativamente o desempenho acadêmico.

Definido o objetivo do estudo, percebemos que o marco teórico demandava a explicitação inicial de conceitos como procrastinação, rendimento e/ou aprendizagem, avaliação, cientes de que outros iriam surgir, pois para compreender as informações coletadas é preciso "não anestesiar a surpresa, não ocultar a complexidade, prosseguir interrogando o enigma" (MORIN, 2017). ${ }^{3}$

\footnotetext{
${ }^{3}$ Disponível em <http://www.historia.uff.br/tempo/artigos livres/artg1-2.pdf> Acesso em: 28 abril 2017.
} 
Os conceitos foram divididos entre os alunos do componente, ficando responsáveis em elaborar um texto com as características de um referencial teórico sobre ele, identificando o que outros autores tinham teorizado sobre os conceitos definidos por nós como básicos/iniciais para a compreensão do fenômeno. Os alunos realizaram a tarefa conforme o combinado e socializaram seus textos em uma aula destinada para isso.

Nesse espaço, vamos apenas definir brevemente cada conceito, a fim de esclarecer ao leitor nossos achados principais. Em relação ao conceito de procrastinação, apesar de muitos estudantes desconhecerem seu significado, os sintomas que caracterizam um sujeito procrastinador parecem estar presentes nas atitudes de um número expressivo de alunos e também de alguns professores do contexto universitário estudado, especialmente no que se refere "ao ato de adiar algo ou prolongar uma situação para ser resolvida depois". ${ }^{4}$

Em decorrência disso, em muitos casos, essa atitude pode causar a não entrega ou a entrega de uma tarefa com a qualidade afetada negativamente pelo fato de ter sido feita às pressas, em razão de ter sido "deixada para depois". Pode acontecer também que o professor não pratique a retroalimentação ${ }^{5}$, não devolvendo os trabalhos, no prazo ou fora deles, não oportunizando que o aluno reflita criticamente sobre seu processo, não se auto avalie.

Gonzáles-Pienda, Nuñes e Rosário (2006) contribuem para a compreensão da palavra, afirmando que

\begin{abstract}
A procrastinação é o adiamento sucessivo das tarefas e está relacionada com um padrão de baixo controle associado a uma má gestão do tempo, incompetência volitiva e irresponsabilidade; mas também a um padrão de evitamento associado ao medo de falhar e à ansiedade. (GONZÁLES-PIENDA, NUÑES, ROSÁRIO, 2016, p. 143).
\end{abstract}

Paradoxalmente, apesar de muitos desempenharem a procrastinação, o conceito é pouco explorado, sendo um fenômeno pouco conhecido pelos que a praticam. Para justificar essa afirmação, desenvolvemos uma pesquisa exploratória para identificar estudos realizados sobre procrastinação acadêmica no Brasil. Encontramos quinze publicações referentes ao tema.

Destacamos o estudo de Costa e Júnior (2017), que realizaram uma revisão sobre a procrastinação (2005-2015) informando que a maioria das publicações sobre o fenômeno no período estudado se referem ao contexto acadêmico.

\title{
Sobre rendimento acadêmico
}

O conceito de rendimento acadêmico utilizado nesse estudo, se refere ao resultado da avaliação, baseada em critérios especificados por cada instituição, expressado em um número (nota) ou um conceito que, aliado ou não a outros critérios, define a aprovação e/ou reprovação em um componente curricular.

A nota, ou os resultados que o estudante alcança dependem da articulação dinâmica de fatores pessoais e contextuais (ALONSO TAPIA, 2014). Os fatores pessoais se referem ao tipo de motivação que move o sujeito, seu autoconceito, definição de metas, atitudes proativas coerentes com as metas, desenvolvimento de estratégias para alcançá-las. Fatores pessoais esses que interagem

\footnotetext{
${ }^{4}$ Disponivel em: <https://www.significados.com.br/procrastinar/> Acesso em: 04 nov. 2016.

${ }^{5}$ A retroalimentação precisa acompanhar os processos de ensino e de aprendizagem, com a intenção de oferecer ao aluno, imediata e oportunamente, informação sobre a qualidade de seu desempenho para que realize as correções necessárias para aprofundar suas competências e habilidades (ALONSO TAPIA, 2014).
} 
dinamicamente com o contexto educacional, composto pelo conteúdo, as estratégias de aprendizagem, os colegas, os professores, o dia a dia acadêmico, retroalimentando (positiva ou negativamente) e encaminhando decisões, escolhas, atitudes contínuas.

\section{Sobre aprendizagem}

"Aprender é este vaivém sem fim de desconstrução e reconstrução, no qual nos esquematizamos e nos liquefazemos" (BAUMAN, 2007, p 34).

Ao encontro da ideia de Bauman (2007), percebemos, como Freire (1996), Vygotsky, Wallon, entre outros que aprender é produzir relações entre uma informação "nova" e o conhecimento prévio. Como afirma Morin (2012) "o conhecimento só é conhecimento enquanto organização, relacionado com as informações e inserido no contexto destas" (p.16).

$\mathrm{O}$ ato de aprender transforma o aprendiz, informações são reconstruídas, ressignificadas na interação com a base conceitual que o sujeito já elaborou, com o outro e no confronto com a realidade. Nas condições de verdadeira aprendizagem, os educandos vão se transformando em reais sujeitos da construção e da reconstrução do saber ensinado, ao lado do educador igualmente sujeito do processo". (FREIRE, 1996, p. 26).

Complementando essa ideia, Morin (1999) percebe que a aprendizagem demanda a articulação do reconhecimento e da descoberta. "Aprender comporta a união do conhecido e do desconhecido" (MORIN, 1999, p. 70).

Coerente com essa concepção de aprendizagem, que reconhece a necessidade de diagnosticar o conhecimento prévio do sujeito sobre o conteúdo que se pretende ensinar, concebemos que "ensinar não é transferir conhecimento, mas criar as possibilidades para a sua produção ou a sua (re) construção" (FREIRE, 1996, p. 21).

\section{Sobre avaliação}

De acordo com alguns teóricos, o uso da avaliação escolar de modo autoritário, elitista, voltada para seleção social e ideológica vem sendo feita há anos (BOURDIEU, 1982; LUCKESI, 1986, PERRRENOUD, 1984, VASCONCELLOS, 1998), sendo talvez essa a representação social da avaliação que os alunos oriundos da educação básica tragam quando ingressam no ensino superior. Nas entrevistas realizadas, em várias situações, os alunos manifestaram não ter clareza dos objetivos de aprendizagem das tarefas solicitadas "não tenho como saber o que o professor quer que eu faça com esse texto", nem dos seus critérios avaliativos.

O ideário pedagógico coerente com a concepção de reconstrução do conhecimento (VASCONCELLOS, 1998; MORIN, 2000; HOFFMANN, 2008) percebe a avaliação como um processo diário, contínuo, cujo objetivo principal é o de diagnosticar/identificar se as estratégias didáticas planejadas pelo professor para apresentar o conteúdo, estão indo ao encontro do conhecimento prévio dos alunos, oportunizando que ele reconstrua, e ressignifique o conhecimento, em uma base conceitual já existente.

Segundo Caldeira (2000), a avaliação necessita ser percebida como

[...] um meio e não um fim em si mesma; está delimitada por uma determinada teoria e por uma determinada prática pedagógica. Ela não ocorre num vazio conceitual, mas está dimensionada por um modelo teórico de sociedade, de sujeito, de educação e, consequentemente, de ensino e de aprendizagem, expresso na teoria e na prática pedagógica. (CALDEIRA apud CHUEIRI, 2000, p. 51). 
O conceito de avaliação, como o de qualquer outro fenômeno, é complexo, multifatorial, dependente-autônomo do contexto no qual é utilizado. Não é um conceito que possa ser analisado isoladamente, pois ele é dependente das concepções de ensino, de aprendizagem, de sujeito, de contexto, do papel do professor, das normas da instituição entre outros. Quatro tipos complementares de avaliação foram identificados:

a) a diagnóstica, utilizada na introdução de um conteúdo de aprendizagem, para identificar o conhecimento prévio sobre o tema do componente e os conceitos a ele relacionados;

b) a (in)formativa: utilizada durante o processo de aprendizagem, através de estratégias planejadas pelo professor, para acompanhar de modo sistemático seus alunos, identificando de onde partiram, em relação ao conteúdo, e como estão avançando a cada encontro em relação a reelaboração do conhecimento, a introdução de novas informações e/ou, se necessário, procedendo a algum redimensionamento nas estratégias utilizadas;

c) a avaliação somativa, que tem por objetivo identificar as aprendizagens reconstruídas, avaliando o aluno em relação a ele mesmo, de onde partiu e como se encontra;

d) e a autoavaliação, a (auto) observação e a reflexão crítica sobre seu desempenho, elaboração de ideias, avanços, considerado um meio eficiente para o sujeito (aluno/professor) identificar e analisar atitudes e procedimentos, bem como sua adequação para o alcance dos objetivos traçados previamente.

Ao pesquisar avaliação no ensino superior, nos deparamos com divergências e convergências de conceitos, estratégias e opiniões. Tanto a revisão da literatura, quanto falas das entrevistas, nos mostraram que alguns professores utilizam apenas a avaliação somativa, através de provas tradicionais, com perguntas que demandam cálculos trabalhosos e/ou respostas dissertativas com formatos definidos, cujas intenções parecem ser de verificar se o aluno é capaz de memorizar e repetir o que ouviu em aula.

Outros relatos, encaminham para professores que avaliam através de trabalhos escritos ou em apresentações de grupos, havendo falas que indicam que muitos professores não costumam fornecer retroalimentação dessas produções, não comentando suas percepções, não apontando imperfeiçoes ou incompletudes, não sugerindo estratégias para avançar.

Alguns relatos informais de alunos, referem casos de trabalhos mal elaborados, bem avaliados, e alunos que confessam desconfiar que alguns professores nem sequer leem os trabalhos. Essas são também percepções de pesquisas informais, desenvolvidas em anos de escuta. Porém, como são recorrentes, julgamos necessário assinalar.

Durante a elaboração da revisão da bibliografia sobre procrastinação e os conceitos definidos a priori (rendimento, aprendizagem, ensino e avaliação), nos deparamos com o conceito de autorregulação da aprendizagem (ZIMMERMAN, 2000) que nos pareceu relacionado com o tema principal da pesquisa, podendo contribuir para seu objetivo. A seguir, apresentamos algumas ideias.

\section{Sobre autorregulação da aprendizagem}

Segundo Zimmerman (2000), a autorregulação da aprendizagem se refere a qualquer pensamento, sentimento ou ação criada e orientada pelos próprios alunos para a realização dos seus objetivos. Está relacionada também com a (re) construção de competências para planejar e direcionar autonomamente estratégias de resolução de tarefas acadêmicas e obstáculos inerentes a elas. 
É um processo ativo e construtivo através do qual os sujeitos estabelecem objetivos para sua aprendizagem e depois buscam aprimorar o pensamento, a motivação e o comportamento, guiados pelos objetivos e pelas características do contexto envolvente. As investigações sobre a cognição têm sugerido que os estudantes que aprendem "mais/melhor" diferem dos que aprendem "menos/pior" também na forma em que autorregulam seus processos mentais e utilizam estratégias de aprendizagem. (SCHWARTZ, 2008).

Autorregulação e autonomia são conceitos imbricados que indicam a habilidade que do sujeito de se (auto) gerir, de escolher, planejar, desencadear e monitorar as ações. A autorregulação, assim como a autonomia, são construtos processuais, que dependem/são apoiadas por experiências bem-sucedidas ao longo da escolaridade, que encaminham para a percepção de si mesmo como sujeito capaz de aprender, com consciência de ser competente para decidir e originar a ação e de que é possível, através de estratégias aprendidas, autorregular o acompanhamento/desenvolvimento do que se propôs a fazer.

Nesse sentido, percebemos que a autorregulação da aprendizagem está relacionada com a criação de estratégias para realizar as tarefas demandadas, que por sua vez, dependem da explicitação dos objetivos de aprendizagem, dos critérios de avaliação, das expectativas do professor em relação ao que solicitou. Autorregular a aprendizagem é processual, dependente/autônomo (MORIN, 2000) das interações do sujeito, nos diferentes contextos que vivenciar, se refere a reconstruir atitudes que podem contribuir para que não ocorra procrastinação de tarefas.

\section{Metodologia}

Após elaborada e socializada a revisão bibliográfica sobre o tema e os conceitos inter-relacionados, cada pesquisador ficou encarregado de realizar duas entrevistas, gravá-las e transcrevê-las e descrevê-las ${ }^{6}$, trazendo o material para a aula, a fim de procedermos a análise das informações coletadas. A seguir relatamos a síntese do caminho metodológico percorrido.

Conforme já mencionamos, optamos pela abordagem qualitativa de pesquisa (MINAYO, 2002; GERHARDT; SILVEIRA, 2009), porque nosso objetivo não era o de mensurar e sim compreender relações entre fenômenos. Utilizamos como instrumento metodológico de coleta de informações a entrevista semiestruturada. $E$ a análise das informações foram realizadas com base na técnica de análise de conteúdo textual e discursiva (GALLIAZI; MORAES, 2006; MORAES, 2003).

Foram realizadas cinco entrevistas gravadas e transcritas com estudantes universitários do contexto mencionado. As entrevistas foram agendadas previamente com os participantes e iniciavam com o questionamento "como tu administras as tuas tarefas acadêmicas? "Elaboramos o questionamento em grupo, e o fizemos de modo a induzir o menos possível o entrevistado.

Ao convidar os colegas para participarem, explicávamos que estávamos fazendo uma pesquisa para o componente Metodologia de Pesquisa, e que precisávamos da cooperação deles. Explicamos que as informações sobre os entrevistados seriam mantidas em sigilo, usando no texto pseudônimos. Foram sujeitos de pesquisa dois estudantes do sexo masculino e três alunas do sexo feminino, respectivamente nomeados por nós como Rodrigo, William, Ana, Helena e Marina.

Após realizarmos as entrevistas, transcrevemos os áudios e procedemos a análise das informações através da análise de conteúdo textual e discursiva proposta por Galiazzi e Moraes

\footnotetext{
${ }^{6}$ Com esses três procedimentos tínhamos o objetivo de ficar "impregnados" das falas dos entrevistados a fim de proceder a análise das informações (MINAYO, 2012).
} 
(2006) cujos passos se referem a preparação das informações, a unitarização, categorização, descrição e a interpretação.

Do processo de análise de conteúdo textual e discursiva descritas por Galiazzi e Moraes (2006), emergiram quatro categorias: o acúmulo de tarefas, o adiamento de tarefas, a atribuição de significado para a tarefa e a autorregulação da aprendizagem. Na próxima seção, serão apresentadas a descrição das categorias, a seleção de alguns excertos e/ou citações das entrevistas semiestruturadas e revisão da bibliografia, utilizando a técnica de triangulação (TRIVINOS, 1987) para demonstrar como interpretamos as informações.

\section{Resultados e discussão}

\section{Categoria 1: acúmulo de tarefas}

Os estudantes entrevistados convergiram para a ideia de quantidade "enorme" de tarefas que são solicitadas por seus professores ao longo dos semestres como motivo para adiá-las. A interpretação do discurso implícito nessas falas indica a percepção da impossibilidade de realizar todas, o que pode já desanimar a tentativa.

Segundo Enumo e Kerbauy (1999), acumular a realização das tarefas é um dos fatores que encaminha para a procrastinação, já que a equação "tempo $\mathrm{x}$ número de tarefas" geralmente não fecha. Esse tipo de situação pode ocasionar sentimentos como culpa e irritação, mas, proporciona também um certo alívio por adiar uma tarefa que causaria incômodo ou estresse, gerando sentimentos antagônicos.

Bariani e Sampaio (2011) descreveram algumas razões citadas pelos alunos para adiarem as tarefas: falta de tempo, insatisfação em realizar a tarefa e preguiça. Sobre esse fato, as autoras (2011) argumentam que

\footnotetext{
[...] que estudantes com altos índices de procrastinação perceberam que essa tem impacto negativo na qualidade de trabalhos, diminui as chances de atingirem objetivos acadêmicos e favorece um desempenho acadêmico global menor que o esperado. (BARIANI E SAMPAIO, 2011, p. 244).
}

Para fazer um tipo de aproximação com essa realidade, podemos pensar que uma semana regular de aulas, nos cursos dos participantes, é composta por, pelo menos, cinco componentes curriculares diferentes. Se cada professor solicitar algum tipo de tarefa para a próxima aula, os alunos regulares terão que no mesmo dia, frequentar aula e elaborar uma das tarefas solicitadas. Dependendo do tipo e da quantidade de tarefas propostas, elas podem gerar um acúmulo, que, como já dissemos, pode desencadear a procrastinação.

Segundo o relato de uma das estudantes entrevistadas a quantidade de tarefas solicitadas inviabiliza estratégias inicialmente planejadas para lidar com elas, ocasionando a necessidade de postergação de algumas. Ana, relata que inicia o semestre com a estratégia de não faltar às aulas, ficando assim ciente de tudo que é solicitado. Porém, a quantidade de tarefas que vão sendo solicitadas ao longo das semanas, a obrigam a escolher entre ir a aula ou realizar uma tarefa solicitada para outra. $\mathrm{O}$ que resulta no acúmulo e, consequentemente, no fracasso do objetivo de acompanhar tudo o que é solicitado. A estudante comenta que: 
[...] é, no início [início do semestre]. No primeiro mês até funciona [estratégia de não falar aula], mas depois é... Começa a vir muita... Muita tarefa, então, muita coisinha, então eu acabo não conseguindo dá conta. (Ana - Transcrição da entrevista semiestruturada).

Podemos identificar no excerto acima que a percepção da quantidade de tarefas solicitadas não favorece o esquema de organização da aluna. A aluna ainda comentou, na entrevista, que já foi reprovada por infrequência em razão do acúmulo de tarefas e assume dar prioridade para determinado componente curricular quando enfrenta o acúmulo, o que resulta em escolher faltar as aulas dos componentes curriculares que julga "não tão importantes", para realizar tarefas que "julga/percebe" como mais importantes.

Essa constatação, do uso de um tipo de juízo de valor existente entre os componentes curriculares do curso, comum aos cinco sujeitos, serviu de indício para a categoria que se refere a atribuição de significado de tarefas e as possíveis articulações com 0 ato de procrastinar. Identificamos, na fala dos entrevistados, evidencias de estratégias "simples" de solução, como a de priorizar atividades solicitadas por professores de componentes obrigatórios em detrimento dos eletivos. Queríamos seguir investigando se havia outro tipo de relações.

Ana relata "estar tentando ser um pouquinho mais organizada" na tentativa de "evitar o acúmulo de tarefas e o mau desempenho acadêmico", no entanto, a aluna afirma que "sua organização para lidar com as tarefas acadêmicas acaba sendo malsucedida, e elas acumulam", gerando um círculo vicioso, alimentando sua percepção de incapacidade de realizar tudo.

Em contraponto, também foi possível evidenciar que alguns dos entrevistados desenvolveram estratégias para evitar o acúmulo de tarefas e, ao contrário de Ana, obtiveram êxito. Os estudantes relataram que organizam agendas, pastas móveis, pastas digitais e planilhas, o que se alinha com as concepções de Polydoro, Rosário e Sampaio (2013), que em seu estudo sobre a autorregulação da aprendizagem e procrastinação acadêmica sugerem que alunos que (auto) regulam adequadamente seu processo de aprendizagem, evitam a procrastinação acadêmica.

No que tange o acúmulo de tarefas presentes nos relatos, os entrevistados comentam que a solicitação de muitas tarefas acadêmicas costuma "ser uma característica do curso" que estudam. Para entender melhor essa afirmação, fomos pesquisar os planos de ensino do curso, ${ }^{7}$ a fim de identificar o número de tarefas solicitadas por semestre em componentes obrigatórios e eletivos.

Nossa investigação mostrou que as tarefas comumente solicitadas são leituras de textos para seminários, produção de textos, trabalhos em grupos. Inicialmente, nos planos de ensino entregues no início dos semestres não foi possível identificar a existência de excesso de tarefas em relação ao tempo destinado para elas, porém foi comentado pela totalidade dos entrevistados, que ao longo do semestre, nas aulas, são inseridas outras atividades, que não constavam previamente nos planos de ensino.

\section{Categoria 2: adiamento de tarefas}

A categoria denominada "adiamento de tarefas" está bastante relacionada ao acúmulo de tarefas, porém, pode acontecer sozinha. Ela foi identificada em convergências de falas sobre o uso dessa estratégia para atender algumas das demandas, priorizando trabalhos de outros componentes curriculares ou substituindo a realização dos trabalhos por atividades de lazer.

Alguns entrevistados justificam o uso da estratégia de adiar tarefas, entregando-as com atraso ou não as realizando, porque não são "apenas acadêmicos", "temos vida fora da universidade".

\footnotetext{
${ }^{7}$ Os planos de ensino foram encontrados no site da Universidade pesquisada.
} 
Percebem como se o fato de terem tarefas, responsabilidades fora do contexto acadêmico, não serem lembrados/considerados nas demandas da maioria dos professores.

Em relação ao conflito entre vida pessoal e vida acadêmica, a estudante Marina relata que muitas vezes é necessário escolher entre fazer tarefas acadêmicas ou passar momentos com a família ou amigos, por exemplo, o que gera sentimentos negativos com as tarefas acadêmicas, pois não as julga "prazerosas" e observa as mesmas como um empecilho para o seu "lazer", pois afirma que só consegue se manter em dia com as tarefas acadêmicas "às custas de lazer".

Esse fator de preferir passar momentos de lazer com a família e/ou amigos do que realizar uma tarefa acadêmica ou ainda preferir eventos percebidos como "prazerosos", fora do âmbito acadêmico, vai ao encontro do que Sampaio e Bariani (2011) afirmam que os estudantes que praticam a procrastinação comumente sentem "prazer" durante o ato de procrastinar, mas o mesmo é seguido de "desespero", ou seja, postergar uma tarefa acadêmica, para realizar outra vinculada a um prazer momentâneo, gera desconfortos.

Referendando essa ideia, Brito e Bakos (2013) afirmam que "procrastinar é estressante e ruim, pois, quando se adiam tarefas ou decisões, se desperdiça muito tempo pensando naquilo que se está evitando " (p. 39).

Nos chamou a atenção que nenhum dos entrevistados mencionou realizar tarefas acadêmicas com o intuito de aprendizagem ou que sentem prazer ao realizá-las. Os sujeitos de pesquisa relataram que procuram "cumprir" as tarefas em curto, médio e longo prazo, visando unicamente a avaliação do professor e consequente aprovação no componente.

\section{Categoria 3: a percepção do significado da tarefa solicitada}

Essa categoria emergiu baseada em falas como as já comentadas, que sinalizavam para um tipo de escolha das tarefas que seriam adiadas. Escolhas são baseadas em critérios (implícitos ou explícitos) e decidimos aprofundar a investigação sobre esses, categorizando as falas relacionando com a percepção do significado delas pelos acadêmicos. De acordo com nossa categorização, o critério apontado pela maioria se referia a "matéria/conteúdo importante", e quando questionados quais seriam esses, convergiram para os componentes denominados obrigatórios e para aqueles que eram ministrados com professores sabidamente "menos" flexíveis.

A atribuição de significado a tarefa depende de pelo menos dois fatores: as relações que os alunos são capazes de estabelecer entre a tarefa e os seus conhecimentos prévios e que possam ser capazes de compreender as implicações futuras de sua realização - o que são demandados a aprender com a tarefa e com quais critérios serão avaliados. Estes são fatores que estão sob controle do professor (ALONSO TAPIA, 2014). Dependem, porém, da clareza das intenções de aprendizagem da tarefa escolhida, do conhecimento dos alunos sobre o tema e da adequação do procedimento/tarefa planejada.

Os alunos, ao serem demandados a realizar alguma tarefa, geralmente, elaboram implícita ou explicitamente a pergunta: "para que será que serve isto? "Esse questionamento indica a busca de um significado para o que é preciso fazer e para que. As respostas, ou a ausência delas, condicionarão as ações do sujeito, a quantidade e a qualidade do seu envolvimento, do seu esforço e da sua persistência na atividade. (ALONSO TAPIA, 2013).

Significar um objeto de conhecimento implica em explicitar as aprendizagens que ele pode oportunizar e no que elas podem contribuir ou serem "úteis". Para que os acadêmicos consigam compreender esses dois aspectos, há necessidade de desenvolver estratégias didáticas que visam a 
elaboração de relações com o conhecimento prévio sobre o tema, provoquem curiosidade, sejam desafiadoras, que a tarefa acene com algum tipo de satisfação de uma necessidade, mesmo que ela não esteja tão consciente no início (VASCONCELLOS, 1994).

A referência à utilidade ou à relevância da aprendizagem proposta pode se concretizar quando o sujeito percebe a existência de um problema que suscita curiosidade e desejo de conhecer. Além disso, explicita-se a utilidade, exemplificando com situações cotidianas, mostrando para que podem necessitar/utilizar este conhecimento, o que permite também o estabelecimento do significado desta aprendizagem. É importante também a explicitação de diferentes usos para o mesmo objeto de estudo, visto que os motivos que trouxeram os alunos para esse curso, geralmente, também são distintos (ALONSO TAPIA, 2005).

Os alunos se sentem mais envolvidos e conseguem produzir de modo mais eficiente quando o professor tem o cuidado de, por um lado, refletir sobre o tipo de dúvidas e questionamentos que a tarefa pode suscitar e, por outro, buscar responder, para si mesmo, algumas delas, pois é importante também ter a clareza de que a atividade solicitada é condicionada pela qualidade dos enunciados (MEIRIEU, 2005).

O professor que trabalha a partir das representações dos alunos tenta reencontrar a
memória do tempo em que ainda não sabia, colocar-se no lugar dos aprendizes, lembrar-se
de que, se não compreendem, não é por falta de vontade, mas porque o que é evidente para
o especialista parece opaco e arbitrário para os aprendizes (PERRENOUD, 2000, p.29).

Não é possível considerar que alguns significados são "óbvios". O óbvio é subjetivo, dependente-autônomo do conhecimento prévio de cada um, e os acadêmicos são oriundos de uma outra cultura escolar, em que as demandas, os objetivos de aprendizagens eram distintos. É necessário considerar que "nossas certezas são para nós mesmos tão óbvias, claras e definitivas que nos impedem de perceber que são tão somente formas óbvias, claras e definitivas que temos de olhar para o que somente nós vemos (LACERDA, 2002, p.39)".

Ao longo da revisão teórica sobre o tema, percebemos que não são "meros" detalhes o modo de elaborar o enunciado de uma atividade, nem a explicitação dos objetivos de aprendizagem que se quer oportunizar, bem como os critérios avaliativos que necessitam ser esclarecidos, para que haja envolvimento produtivo nas tarefas propostas, percebendo ou não se os objetivos foram alcançados, como e porquê.

Essas percepções, bem como as aprendizagens construídas ao longo de cada aula precisam ser explicitadas em um momento planejado para isso, para que os sujeitos recebam retroalimentação de suas ações/pensamentos/ideias, e possam reconduzir suas tarefas se houver a necessidade.

\section{Categoria 4: autorregulação da aprendizagem}

Essa categoria emergiu das falas que indicavam os diferentes modos de gerenciar a realização (ou não) das tarefas. Os sujeitos entrevistados mencionaram diferentes estratégias, no entanto, todos confessaram que procrastinavam alguma tarefa.

A autorregulação da aprendizagem se refere as estratégias que o sujeito utiliza para gerenciar seus compromissos acadêmicos. Os alunos podem ter em maior ou menor grau essa capacidade de autorregular sua aprendizagem, porém os pesquisadores do tema sugerem que quanto mais elevado seja esse autocontrole, mais autonomia o sujeito terá para os processos de aprendizagem e isso pode afetar positivamente também a sua vida pessoal. 
Foi possível identificar que alguns dos sujeitos da pesquisa evidenciam estratégias para lidar com as suas tarefas acadêmicas que podem estar relacionadas a tentativas de autorregulação da aprendizagem. Helena, por exemplo, citou o hábito de anotar em "papéis coloridos" as tarefas que precisa cumprir durante o semestre e também o de organizar pastas digitais e móveis com a organização dos componentes curriculares que cursa. A aluna, quando questionada sobre como lida com suas tarefas acadêmicas, comenta que:

\begin{abstract}
[...] eu tento sempre anota do que eu vou fazer, né? De cada matéria. Algumas matérias que, por exemplo, precisa de uma pasta... Eu sempre coloco em pastas referentes. (...) É nesse semestre eu tenho estágio, então eu tenho duas pastas diferentes pros dois estágios, tanto no computador quanto pastas é... móveis, que eu levo... É... eu sempre tô manipulando alguma coisa referente a aquelas aulas. Para diretamente o estágio, ela contribuiu muito, porque é... Como são aulas, eu tenho uma projeção daquilo que eu vou fazer, então o material tá ali pré-disposto de uma forma é... linear, da qual eu posso [acessar]... Da qual eu não me perco. (Helena - Transcrição da entrevista semiestruturada).
\end{abstract}

Um indício que indica a relação do uso de procedimentos autorregulatórios com bom rendimento acadêmico é que a entrevistada Helena afirmou, no decorrer da entrevista, que costuma obter excelentes avaliações nas tarefas que executa.

O entrevistado William, relatou que organiza planilhas no caderno e realiza tarefas de acordo com elas. Planilhas são excelentes estratégias de proporcionar a visão do todo, nesse caso, das tarefas a serem realizadas. Dessa forma, William pode se organizar de acordo com o calendário, desenvolvendo estratégias de ir elaborando as tarefas. Ressaltou, porém, que as vezes funciona e outras não.

A entrevistada Marina afirmou não ter estratégias prévias para lidar com as tarefas acadêmica. Apesar de negar que tenha estratégias prévias, a aluna demonstra ao longo da entrevista uma atitude que se alinha com o que percebe Zimmerman (2001 apud SAMPAIO; POLYDORO; ROSÁRIO, 2012) "a autorregulação do aprender trata-se de um processo cíclico, dinâmico e integrado, que se retroalimenta a partir do feedback das experiências de aprendizagem do próprio aluno" (p.120).

As estratégias podem evidenciar a autorregulação, mas pensamos ser importante refletir, novamente, sobre o fato de, nas entrevistas não haver a utilização da palavra "aprendizagem". Os entrevistados se referem sobre a sua organização para "cumprir tarefas". Uma das alunas entrevistadas comentou que a motivação para ser organizada é estar em dia com tarefas e completa que "o objetivo da universidade é estar com as tarefas em dia".

\title{
Considerações parciais
}

Cientes da inexistência de certezas, da incompletude do conhecimento, da impossibilidade de generalização dos achados, das limitações de tempo e de sujeitos entrevistados, elaboramos algumas conclusões parciais.

Quanto ao objetivo de compreender se a procrastinação pode influenciar negativamente o desempenho acadêmico, percebemos que os sujeitos que afirmaram não realizar "adequadamente" suas tarefas tiveram prejuízo em suas avaliações. Essa conclusão foi identificada tanto nas falas que relataram a percepção de relação direta entre procrastinar e mau desempenho, quanto na revisão da bibliografia que foi apresentada ao longo do texto. 
O bom rendimento acadêmico é expresso, geralmente, na habilidade da produção de respostas "adequadas" as demandas e/ou expectativas propostas por professores e tarefas. Por sua vez, essas demandas trazem implícitas concepções de ensino, de aprendizagem, de sujeito, de mundo, entre outras. Para elaborar adequadamente as "respostas", o sujeito precisa ter clareza do que é esperado dele, qual aprendizagem precisa reconstruir, com que objetivos e com que critérios será avaliado. Se não houver a explicitação, o conhecimento prévio de "cumprimento de tarefas" que a maioria dos sujeitos traz da educação básica, irá prevalecer, assim como a procrastinação.

Muitas vezes os alunos relatam que têm muitos textos para ler para aquela semana. Quando questionados sobre o "para que" dessas leituras, geralmente respondem que o professor de tal componente solicitou. Parece ser óbvio que se o componente traz no nome algo relacionado no texto, o texto precisa ser lido. Se questionados sobre o que precisam aprender com essa leitura? Qual o objetivo de aprendizagem? Ficam surpresos com a pergunta e sem respostas, o que evidencia a ausência de clareza dos objetivos das tarefas, o que poderia facilitar a sua realização e evitar a procrastinação.

Os sujeitos indicaram que o acúmulo de tarefas, ocasionado pela quantidade de atividades solicitadas é um dos principais fatores para gerar o adiamento. Mencionaram também o conflito gerado pelas demandas da vida acadêmica e da vida pessoal, a ausência de prazer na realização tarefa, o que indica dificuldades de percepção dos objetivos das atividades, de relacionar desenvolvimento de tarefas como algo produtivo. Apontaram também a preguiça, complementando a lista dos fatores que geram a procrastinação e contribuem para o mau rendimento acadêmico.

Com a pesquisa foi possível identificar, que já no início do semestre existe um sentimento de resignação com "impossibilidade/incapacidade" de realizar tudo o que são demandados, o que faz com que desanimem antes mesmo de tentar, essa atitude nos encaminhou para o conceito de "desamparo aprendido", que se refere a um estado de depressão ou de perda de esperança que acompanha a crença de que mesmo com muito esforço, por melhor que se tente fazer as coisas, o fracasso, o não conseguir alcançar os resultados desejados, é inevitável (COVINGTON, 1998). Essa ideia gerou o desejo dos participantes de aprofundar o conceito em outra ocasião.

O estudo, desenvolvido no componente curricular Metodologia de Pesquisa, objetivava aprender os passos básicos de uma investigação e os alunos participaram ativamente do processo. Muitas tarefas foram encaminhadas, e ao longo do processo, nenhuma foi procrastinada. O que nos fez pensar que a explicitação prévia dos objetivos de cada tarefa solicitada dentro e fora de sala de aula pode ter colaborado para que o grupo de alunos compreendesse o porquê de realizar o que era solicitado, sabendo o que era esperado deles, percebendo a importância significativa do componente curricular e ampliando o conhecimento reconstruído.

Terminamos o estudo articulando os objetivos do componente e da pesquisa em si, concluindo que a elaboração de uma estratégia de organização de tarefas pode contribuir para minimizar a procrastinação acadêmica, porém ideias como "automatismo de repetição" iniciando, muitas vezes, cursos com atitudes e procedimentos aprendidos em outro contexto escolar, no modo "cumprir tarefa", sem serem acolhidos com a explicitação das mudanças de expectativas, sem perceber que aprender pode ser significativo e prazeroso, quando explicitados os "objetivos", os "procedimentos", os "critérios avaliativos", contribuíram para que os pesquisadores refletissem criticamente, percebessem que ao

\footnotetext{
${ }^{8}$ (SELIGMAN, 1975; SMILEY; DWECK, 1994; COVINGTON, 2003; SCHWARTZ, 2013).
} 
longo desse componente não haviam procrastinado tarefas e que tinham aprendido metodologia de pesquisa na prática, realizando uma que está sendo compartilhada nesse artigo.

Muitas dúvidas foram desencadeadas. Concluímos o estudo desejando investigar a existência de componentes planejados com a explicitação dos objetivos de aprendizagem, dos critérios avaliativos e com acompanhamento processual do docente, retroalimentando os alunos, incentivando atitudes autônomas, autorreguladas, além do conceito do desamparo aprendido. Identificar esses componentes e pesquisar se, nesse caso, o rendimento dos acadêmicos é influenciado positivamente por esse contexto poderá ser nosso próximo desafio.

\section{Referências}

ALONSO T. J. Evaluación Psicopedagógica y Orientación Educativa. Madrid: Síntesis, 2014.

BARBOSA, M. R. L. S; ROCHA, A. P. M. AVALIAÇÃO: Uma prática constante no processo de ensino e aprendizagem. Revista da Católica, Uberlândia, v. 3, n.5, p. 1-12-12, jan./jul. 2011.

BAGGI, C. A. S; LOPES, D. A. Evasão e avaliação institucional no ensino superior: uma discussão bibliográfica. Avaliação, Campinas, v.16, n.2, p. 355-374, jul. 2011.

BRITO, F. S; BARKOS, D. D. G. S. Procrastinação e terapia cognitivo-comportamental: uma revisão integrativa. Revista Brasileira de Terapias Cognitivas, São Paulo, v. 9. n. 1, p.34-41, jun. 2013.

CHUEIRI, M. S. F. Concepções sobre a avaliação escolar. Estudos em Avaliação Educacional, São Paulo, v. 19, n. 39, p. 49-64, jan./abr. 2008.

CÓRDOVA, F. P; SILVEIRA, D. T. A pesquisa científica. In.: GERHARDT, T; SILVEIRA, D.T. (Org.). Métodos de Pesquisa. 1a. ed. Porto Alegre: Editora da UFRGS, 2009. p. 31-42.

CORREIA, R. R; JÚNIOR, P. J. M. Aprendizagem e Procrastinação: Uma Revisão de Publicações no Período 2005-2015. REICE. Revista Iberoamericana sobre Calidad, Eficacia y Cambio en Educación, Madrid, 2017, v. 15, n. 2, p. 111-128, jul./dez. 2017.

COVINGTON, M. La Voluntad de Aprender: Guía para la Motivación en el Aula. $1^{\text {a }}$ ed. Madrid: Alianza Editorial, 2003.

ENUMO, S. R. F; KERBAUY, R. R. Procrastinação: descrição de comportamentos de estudantes e transeuntes de uma capital brasileira. Revista Brasileira de Terapia Comportamental e Cognitiva, São Paulo, v. 1, n. 2, p. 125-133, jul./dez. 1999.

FERREIRA, A. B. H. O minidicionário da língua portuguesa. 5. ed. Rio de Janeiro: Nova Fronteira, 2004. p. 595.

FREIRE, L. G. L. Auto-regulação da aprendizagem. Ciências e Cognição, Rio de Janeiro, v. 14, n.2, p. 276-286, jun. 2009.

FREIRE. P. Pedagogia da Autonomia. Rio de Janeiro: Paz e Terra, 1996.

GALIAZZI, M. C; MORAES, R. Análise textual discursiva: processo reconstrutivo de múltiplas faces. Ciência \& Educação, Bauru, v. 12, n. 1, p. 117-128, abril. 2006.

GERHARDT, T. et al. A entrevista semiestruturada. In.: GERHARDT, T; SILVEIRA, D. T. (Org.). Métodos de Pesquisa. Porto Alegre: Editora da UFRGS, 2009. p. 72.

LACERDA, M. P. Quando Falam as Professoras Alfabetizadoras. Rio de Janeiro: DP\&A, 2002.

MINAYO, M. C. S. (Org). Pesquisa Social: teoria, método e criatividade. Petrópolis: Vozes, 2002. 
MINAYO, M. C. S. Análise qualitativa: teoria, passos e fidedignidade. Ciência e Saúde Coletiva. Rio de Janeiro, v.17, n.3, p. 621-626, mar. 2012.

MORAES, R. Uma tempestade de luz: a compreensão possibilitada pela análise textual discursiva. Ciência \& Educação, Bauru, v. 9, n. 2, p. 191-211, jun./ago. 2003.

MORIN, E. Ciência com consciência. Rio de Janeiro: Bertrand do Brasil, 1996.

MORIN, E. O Método III: o conhecimento do conhecimento. 2 ed. Porto Alegre: Sulina, 1999.

MORIN, E. A cabeça bem feita: repensar a reforma reformar o pensamento. Rio de Janeiro: Bertrand Brasil, 2000.

MORIN, E. Introdução ao pensamento complexo. 2. ed. Lisboa: Instituto Piaget, 1990.

MORIN, E. O método II: A vida da vida. Portugal: Europa-América, 1980.

NUNES, R. C. Panorama Geral da Evasão e Retenção no Ensino Superior no Brasil (IFES). In: XXVII ENCONTRO NACIONAL DE PRÓ-REITORES DE GRADUAÇÃO, Painel. Recife: FORGRAD, 2013. Disponível em: <http://www.forgrad.com.br/apresentacoes/dia1/2013\%20-\%20Painel\%20Forgrad\%20Agosto\%20-\%2 0Evasao.pdf>. Acesso em 29 jun. 2014.

OLIVEIRA, M. K. Jovens e adultos como sujeitos de conhecimento e aprendizagem. In.: RIBEIRO, V. M. (Org.) Educação de jovens e adultos: novos leitores, novas leituras. Campinas: Mercado de Letras/Ação educativa, 2001. p. 15-45.

PERRENOUD, P. Avaliação: da excelência à regulação das aprendizagens: entre duas lógicas. Porto Alegre: Artmed, 1999.

PERRENOUD, P. Dez novas competências para ensinar. Trad. Patrícia Chittoni Ramos. Porto Alegre: Artmed, 2000.

PIAGET. J. Para onde vai a educação? Rio de Janeiro: José Olympio, 1976.

POLYDORO, S. A. J; AZZI, R. G. Autorregulação da aprendizagem na perspectiva da teoria sociocognitiva: introduzindo modelos de investigação e intervenção. Psicologia da Educação, São Paulo, n. 29, p. 75-94, dez. 2009.

POLYODRO, S. A. J. 0 trancamento de matrícula na trajetória acadêmica do universitário: condições de saída e de retorno a instituição. 2000. 167 f. Tese (Doutorado em Educação) Programa de Pós-Graduação em Educação da Universidade Estadual de Campinas, Campinas, 2000.

ROSÁRIO, P; NÚÑEZ, J. C; GONZÁLEZ-PIENDA, J. A. Cartas do Gervásio ao seu umbigo: comprometer-se com o estudar na Educação Superior. São Paulo: Editora Almedina, 2012.

SAMPAIO, R. K. N; BARIANI, I. C. D. Procrastinação Acadêmica: um estudo exploratório. Estudos Interdisciplinares em Psicologia, Londrina, v. 2, n. 2, p. 242-262, dez. 2011.

SAMPAIO, R. K. N; POLYDORO, S. A. J; ROSÁRIO, P. S. L. F. Autorregulação da aprendizagem e a procrastinação acadêmica em estudantes universitários. Cadernos de Educação FaE/PPGE/UFPel, Pelotas, n. 42, p. 119-142, mai./jun./jul./ago. 2012.

SANTOS, L. Vivências acadêmicas e rendimento escolar, estudos com alunos universitários do $1^{\circ}$ ano. 2000. Dissertação (Mestrado) - Universidade do Minho, Braga, 2000.

SCHWARTZ, S. Motivação para ensinar e para aprender: teoria e prática. Petrópolis: Vozes, 2013. 
SCHWARTZ, S; FRISON, L B. Aprendizagem autorregulada e autonomia: articulações com o conceito de erro construtivo. In.: ABRAÃO. M. H. M. B. (Org.). Professores e alunos. Porto Alegre: EDIPUCRS, 2008, p. 355-381.

SILVA FILHO, R. L. L, et al. A evasão no Ensino Superior brasileiro. Cadernos de Pesquisa, São Paulo, v. 37, n. 132, p. 641-659, set./.dez. 2007.

SILVA, A. S. Evasão no Ensino Superior. In.: XXV ENCONTRO NACIONAL DE PRÓ-REITORES DE GRADUAÇÃO (painel), 2012, Uberlândia. Apresentações do XXV ENCONTRO NACIONAL DE PRÓ-REITORES DE GRADUAÇÃO, Uberlândia: FORGRAD, 2012. Disponível em: $<$ http://www.forgrad.com.br/documentos/apresentacoes/apresentacoes_xxv_encontro_nacional_de_pr o_reitores_de_graduacao_antonio.ppt>. Acesso em: 16 mar. 2017.

SILVA, F. et. al. Evasão escolar no curso de Educação Física da Universidade Federal do Piauí. Avaliação (RAIES - Revista da Avaliação da Educação Superior), Campinas e Sorocaba/SP, v. 17, n. 2, p. 391-404, jul. 2012.

SELIGMAN, M. E. P. Helpleness: On Depression, Development and Death. San Francisco: Freeman, 1975.

SMILEY, P. A.; DWECK, C. S. Individual differences in achievement goals among young children. Child development, v. 65, n. 6, p. 1723-1743, Dez. 1994.

TINTO, V. Dropout from higher education: a theoretical synthesis of recent research. Review of Educational Research, Washington, v. 45, n. 1, p. 89-125, winter, 1975. 